\title{
SOCIAL INCLUSION AND THE INFORMATION SYSTEMS FIELD: Why Now?
}

\author{
Eileen M. Trauth \\ The Pennsylvania State University \\ University Park, PA U.S.A. \\ Debra Howcroft \\ University of Manchester \\ Manchester, UK
}

\section{INTRODUCTION}

The Information Systems field and its research conferences have historically focused their attention on issues associated with the development and diffusion of information systems (IS) and the information and communications technologies (ICTs) upon which they are based. Consideration of the social consequences of new systems and new ICTs has generally been limited to investigations of organizational and managerial impact. Thus, this conference, with its focus on those who are socially excluded, represents a noteworthy expansion in scope for the IFIP 8.2 community. In view of this, one might reasonably ask how this topic came to be chosen as the conference theme at this point in time.

With respect to "why now," perhaps the best answer is that by now, in the early $21^{\text {st }}$ century, we have sufficient confirmation of societal disparities, which could perhaps be ameliorated by the use of ICTs, to know that our community should play a role in addressing them. We have ample evidence that changes in the human condition that have accompanied the pervasiveness of information technology have been both positive and negative, intended and unintended, and that they extend beyond the boundaries of the corporation. These consequences have demonstrated that certain countries and certain regions of the world are not full participants in the so-called information society, that certain parts of every population are underrepresented in and underserved by the IT sector. On a daily basis, the consequences of ICTs are revealed in the individuals who directly experience social exclusion.

Please use the following format when citing this chapter:

Trauth, E.M., and Howcroft, D., 2006, in IFIP International Federation for Information Processing, Volume 208, Social Inclusion: Societal and Organizational Implications for Information Systems, eds. Trauth, E., Howcroft, D., Butler, T., Fitzgerald, B., DeGross, J., (Boston: Springer), pp. 3-12. 
In response to this recognition of the need to look at consequences beyond the corporate boundaries, we have chosen social inclusion as the theme for the 2006 IFIP 8.2 conference. In recent years, interest in this theme has emanated from many different quarters. It has occurred in European social policy debates and is of central concern within the social science literature. Despite its common currency, however, the concept remains vaguely defined and, as is often the case with concepts that have political salience, it is highly contested. There are a wide variety of national, competing discourses that refer to exclusion in markedly different ways (Levitas 2005), some of which are contradictory.

The term social exclusion originated in French social policy to refer to those who were administratively excluded by the state. Over time, the term became more widely adopted in Europe to encompass disaffected youth and isolated individuals (Hills et al. 2002). In North America, meanwhile, the term digital divide came into use to refer to people who are cut off in some way from the benefits of mainstream society through lack of adequate access to ICTs. In developing countries, the language of civil and social rights (Cornford and Klecun-Dabrowska 2003) has been used.

Accompanying the political discourse has been that which has come from the academy. Just as competing views are expressed at the political level, academic research has produced differing views regarding the nature of social exclusion. These range from individual behavior and moral values to capitalism and globalization. The concept itself implies a social division between "insiders" (the majority) and "outsiders" (the minority) and places the excluded on the edges of society. An alternative view would look to the inequalities and deprivation that are endemic to society. Conceptualized as the former, the socially excluded are seen as separate rather than understood in relation to the social order as a whole (Byrne 2005). Framed in these terms, a frequently touted solution to the problem is for governments to initiate policy that enables the excluded to cross the boundary in order to become one of the included. Doing so, however, precludes interrogation of structural inequalities. As Fairclough $(2000$, p. 54) comments, "social exclusion is an outcome rather than a process-it is a condition people are in rather than something that is done to them."

Byrne (2005), drawing on the work of Veit-Wilson (1998), brings to our attention the distinction between "weak" and "strong" versions of social exclusion. In this construction, weak exclusion focuses on improving the integration of the excluded into broader society, whereas strong exclusion emphasizes the role of those who are engaged in the excluding. Many of the current social policy debates about this topic and consequent initiatives have been concerned with the weaker form of exclusion, instead of challenging the power of the excluders. Focusing on ways of including the excluded reflects an underlying assumption that there is nothing inherently wrong with contemporary society and that government policy in itself can bring about inclusiveness.

Within the information systems field, much has been written in recent years about the ubiquitous nature and pervasiveness of ICTs (for example, the 2005 IFIP 8.2 conference; see Sørensen et al. 2005) as this phenomenon is seen as having the potential to alter how social, political, and economic relations are played out. The concept of exclusion features prominently in the information society discourse where access to and knowledge of ICTs are portrayed as either exacerbating exclusion or seen as a platform to engender inclusiveness. In reality, the ability of ICTs and networks to herald social 
change and reorganize the economy is far less radical than is often assumed (Thompson 2004). Given this debate, IFIP 8.2 has agreed to consider these issues and expand its focus of study beyond the organizational level in relation to broader concerns affecting citizens more generally.

In the context of ICTs, Castells (1996) argues that social exclusion throughout the world is closely linked with the rise of informational capitalism. He describes it as

the process by which certain individuals and groups are systematically barred from access to positions that would enable them to an autonomous livelihood within the social standards framed by institutions and values in a given context (p. 71).

This position is quite distinct from the discourse concerned with lack of access to material resources and instead refers to the process of being "shut out" from social, economic, political, or cultural systems, which enable integration into society (Walker and Walker 1997).

This process of social exclusion varies over time. Its shifting trajectory is dependent on education, demographic characteristics, social prejudices, business practices, and public policies. Its affect on people has a spatial manifestation as well. Much of the study of social exclusion focuses on individuals and households (for example, access to mobile phones, PCs, Internet connections) but the spatiality of social exclusion is of equal importance (Madanipour 1998) as entire countries, regions, cities, and neighborhoods are seen as excluded. Different types of social experience are predicated on areas of residence, particularly in core global cities (Perron 2004). Globally, ICT penetration is highly uneven (Norris 2001; Sassen 2002) and, as Castells argues, areas that are of little worth from the perspective of informational capitalism are bypassed by flows of wealth and information and deprived of the basic technological infrastructure that allows people to communicate, innovate, and engage as producers and consumers. As a consequence, a dimension of social exclusion is spatial segregation, which marginalizes large groups of people, while simultaneously linking and strengthening through technology those deemed to be of value in the global networks of power.

For these reasons it is appropriate that IFIP 8.2 contribute its voice to the discourse about the exclusion of individuals - who lack access to technological resources - from various societal processes and services. Thus, the theme of this conference, and of the papers in this book, explores the many dimensions of this exclusion. This issue has been the focus of much debate within the social sciences, yet has largely been underresearched in the IS field, despite our concerns with the social and organizational aspects of technology. To the extent that contemporary debates have identified access to information as a key component of poverty, digital exclusion is seen as the problem. Thus, ICTs are portrayed as either exacerbating exclusion or are presented as the solution to greater inclusion. This conference provides us with the opportunity to build upon our strong tradition of studying technology design and use in organizations, and to expand our field of enquiry to consider the processes that engender social exclusion and the issues that derive from it.

This theme invites consideration of social and organizational constraints that result in the underrepresentation of certain groups and, by implication, certain issues. Like- 
wise, it invites consideration of emerging technologies that have the potential to alter social, political, and economic relations. For these reasons, it is timely to expand our focus and progress the study of IS beyond the organizational level of analysis so that we may consider wider societal concerns affecting all citizens.

The papers in this book consider the use of information technology to reproduce exclusion as well as the consequences of social inclusion in the broadest sense to include economic development and geography, political participation, demographic disparities, ethical issues, the role of new ICTs and, finally, the IS profession. In doing so, this book can facilitate a lively debate that may suggest some alternative paths for future researchers to follow.

\section{ECONOMIC DEVELOPMENT AND GEOGRAPHY}

We begin with consideration of economic development issues that are grounded in a specific geographic location. Korpela et al. ask the question, "Can information systems development (ISD) in Africa by African IS practitioners contribute to human development in Africa?" In order to answer the question they focus on whether everyday ISD practice in Nigeria can contribute to people's health there by summarizing the results of over 15 years of European-African research collaboration. Implications are drawn for ISD practitioners and methodological lessons identified to IS research in general. In the discussion the view is expanded from Nigeria to other African and developing countries.

Bagchi et al. continue this discussion by investigating the factors that influence growth rates of ICTs in developing countries, and make comparisons with industrialized countries. Four factors are identified: human development, social structure, institutional factors, and national infrastructure. These are considered in relation to the growth rate at which ICT adoption has taken place. The technologies considered are cell phones, PCs, and the Internet. Bagchi et al. argue that their study reveals that developing and industrialized countries have a similar, yet distinct, range of factors that influence the ICT growth rates.

The discussion concludes with a consideration of American discourses about economic development and the digital divide by Tu and Kvasny. They examine how strands of discourse - institutionalized ways of thinking and speaking - shape debate about the digital divide and urban poverty in America. They are particularly interested in how discourses inform scholarly inquiry into urgent social problems. As information and communication technologies (ICT) are increasingly hailed as drivers of industry and commerce, they believe it will be instructive to examine economic development discourse, which strongly informs the case for bridging the digital divide.

Complementary to these papers is a panel on digital inclusion projects in developing countries, led by Madon, Reinhard, Roode, and Walsham. The panel focuses on the social, political, institutional, and cultural contexts which shape people's lack of access to ICTs and the skills to use them effectively. One response to this is the development of a number of digital inclusion projects, which will be discussed in the context of telecentres in rural areas of India and urban areas of the city of São Paulo, Brazil, and a community-based ICT project in a rural township in South Africa. The panel will 
discuss three key issues in relation to these projects, namely: how these projects can be evaluated; the sustainability of the initiative over time; and the scalability of these projects.

\section{POLITICAL PARTICIPATION}

The problems and consequences of popular political disengagement are welldocumented and the second set of papers considers the role of new information and communication technologies in facilitating or inhibiting political processes. Grönlund et al. present a model for assessing the preconditions for eGovernment in developing countries. Despite the high project failure rate, much attention has been paid to the potential of eGovernment to drive forward the information society agenda; therefore, the authors argue that it is timely to find ways to assess the potential for eGovernment in the hope of avoiding costly failures in the future. A framework is developed which aims to assist the decision-making process before embarking on such a project.

Pieters examines the role of online voting technology in relation to people's experience of democracy. Combining the concept of technological mediation with the political philosophy of John Dewey, Pieters considers the mediating role of online voting technology in the context of developments in the Netherlands, which is one of the first countries to introduce electronic voting on a large scale. It is argued that Internet voting presents new challenges to existing concepts of democracy and that discussing democracy requires reconstruction from the perspective of the new technology.

The focus of the paper by Phang and Kankanhalli is on the participation of youths in electronic democratic processes. Utilizing a survey conducted in Singapore, the authors investigate whether electronic participation forums specifically targeted toward youths have appeal, since this group are increasingly withdrawing from participating in such processes. Drawing on the political science and information systems literature, this study aims to shed light on the issues that contribute to e-participation, highlighting the relevance of offline participation theories to the electronic context.

In a grass roots discussion of political participation, Robinson considers email campaigns as a form of cybersolidarity: action at a distance mediated by use of the Internet in support of trade unions or groups of workers. This paper takes the example of a campaign in support of imprisoned Eritrean trade unionists and examines the social organization and information flows underlying such campaigns. These are discussed in the light of the effectiveness of such actions, their capacity to overcome the global digital divide, current debates on the role of the Internet in the remaking of trade unionism, and labor's capacity to remake the spatial relations of capitalism.

The final paper in this section takes a somewhat different view by considering the effectiveness of social policies aimed at providing and improving access to ICTs and information and, thereby, redressing the digital divide. Maldonado et al. investigate ICT policies as a means to inhibit social exclusion in South Africa by examining how ICT policies in that country are being employed to reduce social exclusion. They do this by analyzing telecommunication laws and one of the ICT initiatives of the South African government: Multi-Purpose Community Centers (MPCCs). ICT policies in South 
Africa were found to address two of the four forms of social exclusion: production of goods and services and civil engagement, spanning both the redistributionist and social integrationist discourses of social exclusion.

\section{DEMOGRAPHIC DISPARITIES}

Social exclusion arises from social inequalities and in every population there are groups who remain underrepresented in the information technology profession and underserved by the ICTs it develops. Typical population groups are based upon such demographic characteristics as gender, race, ethnicity, age, and disability. Three papers in this book deal with the topic of gender. The first paper explores female underrepresentation in the ICT sector in the UK by examining the various challenges that women ICT workers face in relation to their age, their "life stage" and their "career stage." Using eight case studies of individual female ICT professionals of different ages, Griffiths et al. explore these experiences in relation to career and caring responsibilities. Based on their interpretations of the empirical study, the authors have adapted and developed Super's career stage theory to theorize age, life stage, and career stage. One of the key contributions of this paper to the theorization of gender rests on the argument that heterogeneity in experiences is based on collective rather than individual identity distinctions, such as age, socio-economic status, and ethnicity.

In the second paper on gender, Richardson draws on a 5-year longitudinal study to discuss the neglected area of domestication of ICTs in UK households. Adopting a critical perspective to frame the study, she places the domestication of ICTs specifically in its social, political, economic, and historical context. The analysis describes how ICTs are embedded into gendered households and how technologies are manifested in the everyday experiences of women, weaving together their use of ICTs for work, study and leisure into everyday domestic family environments.

In the final paper on gender Gillard and Mitev consider ICT inclusion policies in the UK and contrast the rhetoric of these narratives with the reality of the lived experiences by groups who traditionally remain on the margins, such as part-time women workers with childcare responsibilities. Using an example of a network engineer training scheme that is operational in many UK educational institutions, the authors use the narratives of women in this program to highlight the complexities involved. Their study is situated within a broader political economy and shows how inclusion strategies fall short of expectations, as they fail to address more deep-seated, essentialist assumptions about women working in an industry that remains primarily a male preserve.

The paper by Adams and Fitch considers issues of age in the context of two empirical studies of a ubiquitous technology: the mobile phone. One study is primarily based on the 18 to 25 year-old age group; the other mostly on retired people. The studies show clear differences between age groups and gender in adoption and use of the mobile telephone. They observe that social inclusion for mobile access is closely linked to deeply embedded structures within society, such as those traditionally associated with gender. Thus, technology may be changing these structures such that age may be the new gender. The family or social unit may also be a useful entity to consider in the exclusion debate. Technology is being used to address social exclusion. 
However, Adams and Fitch suggest that while some leveling may result, there may also be different social exclusion fronts emerging.

Finally, Adam and Kreps consider the topic of Web accessibility for disabled people. Much of the Web remains inaccessible or difficult to access by people across a spectrum of disabilities and this may have serious implications for the potential use of the Web for increasing social inclusion. The topic of disabled Web access is introduced through a consideration of four discourses: digital divide, social construction of disability, legal, and the Web accessibility. The lack of dialogue between these discourses permits a passive liberal approach toward disability discrimination to prevail and this political position has become inscribed in widely used automatic software tools, resulting in a reinforcement of the view that Web-site accessibility approval may, in many cases, be deemed an empty shell.

\section{ETHICAL ISSUES}

Two papers in this book consider the ethical dimension of social exclusion. Stahl conducts a critical examination of managing digital divides. He argues that management is part of the construction of the problem and therefore lacks the detached and objective viewpoint required for rational management. Further, the very concept of responsibility, if taken seriously and applied responsibly (here called reflective responsibility) requires a participative approach that contradicts the traditional top-down approach of heroic management. The paper concludes with a discussion of what form of management Information Systems needs to take if it wants to be responsible.

In the second paper, Vaccaro analyzes the ethical perspectives associated with the introduction and use of information and communication technologies in contemporary firms. He presents a three-dimensional ethical model that introduces the transparency concern, and its related impact on the digital divide question, as the new ethical perspective of contemporary business organizations.

\section{TECHNOLOGY AND ITS CONSEQUENCES}

The use of information and communication technologies can be directly linked with social exclusion, although it is manifested in a variety of different ways. This set of papers deals with three themes related to social exclusion and the use of ICTs. The first three papers consider the innovative uses of new technologies to reduce social exclusion. The fourth considers the unintended exclusion that can result from new ICTs. Finally, two papers consider the implications of nonuse of technologies.

Feller et al. consider the use of open source software as a new model for organizational and societal collaboration and community bootstrapping. They present an analysis of 155 research artefacts in the area of open source software in order to identify the kinds of open source project communities that have been researched, the kinds of research questions that have been asked, and the methodologies used by researchers.

Byrne et al. present a case study of an initiative launched by the South African Council for Industrial and Scientific Research to stimulate awareness and promote the 
use of free and open source software in South Africa and the region. The new open source center made use of an African language metaphor to relate the concept of shared intellectual property in software to traditional communal land management. This paper provides a background as to why such a metaphor was chosen as well as some reflection on its effectiveness.

Silva et al. consider the emergent phenomenon of weblogging, which has recently generated much interest in the media, yet has received little attention by IS academics. They conceptualize weblogs by drawing on the concept of communities of practice and the social theory of learning that it proposes. This was used to illustrate the role of weblogging in organizational communication and the potential cultivation of social inclusion for employees working within these organizations.

In the following paper, Davidson et al. offer a deconstruction of a popular management text on Web services, which are often depicted as a highly desirable IT innovation. The article asserts that the Web service architecture takes "people out of the network," removing the need for human activity, while consolidating and extending the role of already powerful social actors in the IT sector, such as large IT vendors and firms. This text is an example of how an IT innovation is promoted in the literature in a progressive way, despite the absence of any consideration of social context and the implications for human actors. Its critical reading raises questions about the social consequences of the dominant organizing vision and the potential for inclusion and exclusion of different groups involved with and affected by IT.

Despite the evidence of the use of ICTs to reduce societal disparities, there remains evidence of the rejection and nonuse of technology. Crump presents a case study of a community computing center that was established in late 2001 in a city council high-rise apartment block in Wellington, New Zealand. The center was part of a project aimed at reducing unequal access to ICT. However, after 4 years of operation, the center was closed. Further analysis revealed that low social capital and the inadequate support of social resources were key factors in the closure of this initiative. Recommendations are made for implementing future projects.

Cushman and Klecun describe findings from a study that explored how nonuse affects individuals' inclusion or exclusion from society and how they can learn to use ICTs to meet their personal goals. The authors argue the need to focus on engagement with technology rather than simple adoption. Since ICTs in general-and Internet use in particular-are experienced technologies, perceived usefulness and perceived ease of use need to be reformulated to recognize limitations on people's ability to construct plans for future action.

\section{THE INFORMATION SYSTEMS PROFESSION}

Issues of inclusion and exclusion are pertinent to the IS profession as well. Three papers and one panel deal with the topic of social inclusion in the information systems community. Elisberg and Baskerville use the theoretical tools of Bourdieu and the concept of capital to show how the mechanism of social inclusion and exclusion operates at the group level in organizational settings. The focus is on communities of practice in a systems development organization and pays consideration to the struggles 
within social practices that occur before groups can gain acceptance among their peers. Elisberg and Baskerville demonstrate how formal organizational structures do not necessarily cater for integration and that communities of practice establish threshold events that organizational peers must satisfy before they are deemed worthy of inclusion within this particular community of practice.

Mayasandra et al. apply postcolonial theory to the development and use of ICTs in developing countries. The authors argue that this theory enables us to view ICTs in developing countries within a broader context, given the long-standing historical relationship of colonialism, neocolonialism, and postcolonialism of the West to the developing world. Using an empirical example of an outsourcing vendor in India, the paper discusses the challenges confronting this firm in its attempt to move away from its previous role as a provider of routine outsourcing jobs and transform itself into a leading global IT consultancy firm. From the perspective of postcolonial theory, it is argued that the global outsourcing phenomenon can be seen as the latest manifestation of colonialism.

Sawyer and Annabi argue that software development methods represent theories on how best to engage the impressively complex and inherently sociotechnical activity of making software. To help illustrate their points, they draw on examples of three software methods: the waterfall approach, package software development, and free/libre and open source software development. In doing this, they highlight the fact that software development methods reflect too often implicitly - theories of how individuals and groups should behave, the tasks that people should do, and the tools needed to achieve these tasks.

Finally, in their panel, Pliskin, Levy, Heart, O'Flaherty, and O'Dea discuss the corporate digital divide between smaller and larger firms. Large organizations invest heavily in ICTs. The situation is somewhat different for small or medium-sized enterprises (SMEs) that invest a much smaller proportion of their revenue. As a consequence, there is evidence that SMEs are unable to employ ICTs strategically, placing them at a disadvantage in relation to larger firms. This panel will present the case for a corporate digital divide between larger and smaller enterprises, arguing that SMEs form an underprivileged sector in terms of ICT usage.

\section{CONCLUSION}

This conference, with its theme of social inclusion, builds upon the debates that have taken place within the IFIP 8.2 community over the past several years. As information and communications technology, and the information systems based upon them, become ever more pervasive, the human impacts - both positive and negative-and the associated societal disparities will continue to arise. It is our hope that the topics discussed at this conference will be considered mainstream in the future.

\section{References}

Byrne, D. Social Exclusion, Maidenhead, UK: Open University Press, 2005. Castells, M. The Rise of the Network Society, Oxford, UK: Blackwells, 1996. 
Cornford, T., and Klecun-Dabrowska, E. "Social Exclusion and Information Systems in Community Healthcare," in M. Korpela, R. Monteallegre, and A. Poulymenakou (eds.), Organizational Information Systems in the Context of Globalization, Boston: Kluwer Academic Publishers, 2003, pp. 291-306.

Fairclough, N. New Labour: New Language, London: Routledge, 2000.

Hills, J., Le Grand, J., and Piachaud, D. Understanding Social Exclusion, Oxford, UK: Oxford University Press, 2002.

Levitas, R. The Inclusive Society? Social Exclusion and New Labour, Basingstoke, UK: Palgrave MacMillan, 2005.

Madanipour, A., Cars, G., and Allen, J. (eds.). Social Exclusion in European Cities: Processes, Experiences and Responses, London: Jessica Kingsley Publishers Ltd., 1998.

Norris, P. Digital Divide: Civic Engagement, Information Poverty, and the Internet Worldwide, Cambridge, UK: Cambridge University Press, 2001.

Perron, D. Globalization and Social Change, London: Routledge, 2004.

Sassen, S. Global Networks, Linked Cities, London: Routledge, 2002.

Sørensen, C., Yoo, Y., Lyytinen, K., and DeGross, J. I. Designing Ubiquitous Information Environments: Socio-Technical Issues and Challenges, New York: Springer, 2005.

Thompson, G. "Getting to Know the Knowledge Economy: ICTs, Networks and Governance," Economy and Society (33:4), 2004, pp. 562-581.

Veit-Wilson, J. Setting Adequacy Standards, Bristol, UK: Policy Press, 1998.

Walker, A., and Walker, C. (eds.). Britain Divided, London: Child Poverty Action Group, 1997.

\section{About the Authors}

Eileen M. Trauth is a professor of Information Sciences and Technology and Director of the Center for the Information Society at The Pennsylvania State University. Her research is concerned with societal, cultural and organizational influences on information technology and the information technology professions with a special focus on the role of diversity within the field. As a Fulbright Scholar in Ireland, Eileen undertook a multi-year investigation of sociocultural influences on the emergence of Ireland's information economy. Her book, The Culture of an Information Economy: Influences and Impacts in the Republic of Ireland, was published in 2000 . She has continued that research by investigating cultural, economic, infrastructure, and public policy influences on the development of information technology occupational clusters in the United States. In 2000, Eileen began an investigation of the underrepresentation of women in the information technology professions by researching women in Australia and New Zealand. She has continued that research with grants from the National Science Foundation and Science Foundation Ireland. She is editor of the Encyclopedia of Gender and Information Technology, published in 2006. Eileen has also published papers and books on qualitative research methods, global informatics, information policy, information management, and information systems skills. She is author or editor of 9 books and over 100 research papers. She is an associate editor for Information and Organization and serves on the editorial boards of several international journals. Eileen received her Ph.D. and Master's degrees in information science from the University of Pittsburgh and her Bachelor's degree in education from the University of Dayton. She can be reached at egrauth@ist.psu.edu.

Debra Howcroft is a senior lecturer in the Accounting and Finance group at Manchester Business School, the University of Manchester. Her research interests focus on technology and organizations within a global context. Debra can be reached at debra.howcroft@mbs.ac.uk. 